\section{The whys of patient centered care}

\section{Mahmoud Hadipour Dehshal \\ Iranian Thalassaemia Society, Tehran, Iran}

My late grandfather kept telling me tales about the influential status of Iranian practitioners (called Hakim) at old times in the lives of the old generations. The tales all purport to the high rank and privilege granted to the practitioners in past as the absolute authority of the community's health who dictated what responsibilities people should take for their health to be ensured. The obsequiousness to the prescription of hakim seemed to be the only guarantee for patients' health and no one but the hakim was entitled the right to talk about the treatment. Still such a physiciandominated procedure called medicalization ${ }^{1}$ is the dominant trend in the health management of the human societies. The question is however if this sort of management can be pursued effectively in the modern era.

Max Weber considers all bureaucratic organizations tended towards the routine decision makings. ${ }^{2}$ Jurgen Habermas updated Weber's theory in the field of juridical systems and made the new word of jurification by which many juridical organizations follow unconditionally the canon law and the predetermined legal trends and the precedence with the consequence of distancing ever before from the general concept of justice. ${ }^{3}$ Herman Melville the famous American author has depicted this gap between the practical law enforcement and justice in his well-known book of Billy Budd. The time Captain Vere despite his personal belief condemned Billy to death sentence just based on the letter of the mutiny act the gap between the law adherence and enforcement with that of justice came to light. ${ }^{4}$

The term medification in the health system is equivalent to jurification in the judicial systems. ${ }^{1}$ There are many different reasons for this phenomenon including the tendency of physicians to follow older practices or the pressure imposed by the health decision makers for lower health costs. ${ }^{1}$ Generally the societies show resistance against change and physicians are no exception. Most frequently the physicians pursue the routine old practice citing the evidence that they are more effective with no necessity for the change in the treatment protocols. ${ }^{5}$ I have had so many observations that the physicians for managing thalassemics have emphasized on the constant 8h-long infusion and refused to use the new oral administration. The engagement of the health decision makers in the disease management and formulation of the therapy protocols encloses care givers within the scope of the routine protocols. Under such circumstances, it is almost impossible to think of change based on the patients' demand.

Physicians' orientation towards routine practices and protocols can be even communicated to patients. The stronger physicianpatient affinity cause of the long term treatment requirement and the transmission of the former's inclination decrease the latter's tendency towards any changes in the treatment protocols. This is much evident at the later decades of life of the patients with hereditary diseases.

The Habermas concern about the supremacy of the daily behaviors over the real goals mostly emerge in the health system in such a way that the medical teams have no reservations in applying the word case to the patients referring to the medical centers. Some days ago a real event manifesting the phenomenon of medification happened to a diabetes patient.

A 39-year old woman with the record of Metformin use referred to the endocrinologist who prescribed insulin for the continuation of her course of treatment. Cause of the demanding character of her schedule and the disinclination of daylong multiple administrations, she refused to carry and use insulin. She then asked her physician for an oral drug but the adroit endocrinologist insisted it to be the violation of the medical protocols. After so much negotiation he agreed to prescribe Lantus the once-daily insulin but the problem was that the insurance companies did not cover it. A few years later I met that lady by chance in a training session of diabetes patients and she came out to be very glad for administering insulin once nightly and sulfonylurea during the day. She told me that she came to know about this method by a general practitioner active in the treatment of diabetes; her postprandial plasma glucose and FbAlc levels were always evaluated to be within the reference range. It prompted me to attempt a simple search and find out about the use of bedtime insulin daytime sulfonylurea in the management of type 2 diabetes. ${ }^{6}$ That lady was not the only patient showing satisfaction with this recent method and a search in the virtual network brought up many reported experiences of its efficacy and the patient compliance.

This single example could be convincing for the great importance to be attached to the special needs of patients for the treatment preferences and the avoidance of the caregivers to place emphasis on medical protocols or to be inhibited by the financial regulations of insurance companies.

The patient orientation is not simply limited to treatment but extended beyond it to the structural design and space planning of the medical centers. ${ }^{7}$ Let me clarify my point. There is a clinic in the northern part of Tehran to where adult thalassemics refer; they have
Correspondence: Mahmoud Hadipour Dehshal, Iranian Thalassaemia Society, Tehran, Iran. E-mail: Mehregan_hadipour@yahoo.com

Acknowledgments: I would like to thank Mr. Mehdi Tabrizi Namini for drafting the article.

Received for publication: 2 August 2015.

Accepted for publication: 11 August 2015.

This work is licensed under a Creative Commons Attribution 3.0 License (by-nc 3.0).

(C)Copyright M.H.Dehshal, 2015

Licensee PAGEPress, Italy

Thalassemia Reports 2015; 5:5473

doi:10.4081/thal.2015.5473

been engaged with thalassemia and its treatment lifelong and are well aware of all the details hereinto. Many specialists and physicians experienced in the thalassemia management consider the clinic deprived of the necessary facilities for the appropriate care. A small dwelling estate has undergone a change of use and has been accommodating the clinic without any drugstore, Intensive Care Unit/ Continuous Care Unit, laboratory, etc. However, many patients covered by this clinic have an exalting attitude for it.

Many thalassemics from different cities across Iran travel to the capital and consider the clinic a suitable treating center. The experienced caring physicians are surprised why it is the case and why so much strong attitude but to me as a thalassemic it is no wonder at all.

Years ago when I was 13 years old in a small city in the north of Iran I used to refer monthly to the hospital for transfusion. Occasionally the hospital was packed with the grievers expecting for the release of their deceased loved ones from the morgue. As a patient with no option but to walk along different hallways to reach the transfusion ward, it was very difficult to tolerate the heavy atmosphere. A new event made it worse and more intolerable to me. In a spring day during transfusion in the hospital emergency room suddenly a critically ill old man was hospitalized the bed next to me and physicians tried to revive him to no avail; he lost his life. I do not remember exactly how long it took him to be taken to the morgue but it still hurts me recalling the time I spent at my 13 years of age beside a corpse. The memory always haunted me and the fear of hospital pushed me to give up the medicine course of study as an option at my university entrance exam. Even at my worst health condition I am reluctant to stay one single night in hospital.

All I am trying to say in which I firmly believe is that the tendencies of thalassemics should be considered for the layout and spacing of thalassemia wards in hospitals. By no 
means does it mean that thelassemia medical centers to be distanced from hospitals or other clinics; it is just a matter of serious attention to hard-to-treat patients such as thalassemics not to be deprived of any other alternative routes but to walk through hospital corridors to reach the thalassemia wards or to stay in hospitals beside chronic or malignant patients.

Patient-centered care is intended to improve the status of patients from the units of throughput to one of the pillars of decision making in patient-oriented treatment. ${ }^{8-10}$ It is impossible to serve this purpose unless physicians find a new perception of what leadership in medical performance is and to shift from the old hakim concept of practitioner that is physician-oriented to a new concept of practitioner in the modern era. ${ }^{11}$ Moreover, the advocacy and insurance systems should try to lower the complexity of the bureaucratic strategies and consider the role of health consumers important in decision making for their own treatment.

\section{References}

1. Arthur W. Frank. Patient-centered care as a response to medification. Available from: http://wakeforestlawreview.com/wp-content/uploads/2010/09/Frank_LawReview_9 .10.pdf

2. Weber M. The theory of social and economic organization, translated by $\mathrm{A}$. M. Henderson and Talcott Parsons. Edited with an introduction by Talcott Parsons. New York: Free Press; 2012 pp 363-373.

3. Habermas J. The theory of communicative action, translated by Thomas McCarthy. Vol 1. Boston: Beacon Press; 1985 pp 316317.

4. Melville H. Billy Budd. London: Constable \& Co.; 1924.

5. Rickert J. Patient-centered care: what it means and how to get there. January 24 , 2012. Available from: http://healthaffairs. org/blog/2012/01/24/patient-centered-carewhat-it-means-and-how-to-get-there/

6. Miller JL, Salman K, Shulman LH, Rose LI. Bedtime insulin added to daytime sulfony- lureas improves glycemic control in uncontrolled type II diabetes. Clin Pharmacol Ther 1993;53:380-4.

7. Otero C, Luna D, Marcelo A, et al. Why patient centered care coordination is important in developing countries? Contribution of the IMIA Health Informatics for Development Working Group. Yearb Med Inform 2015;10:30-3.

8. Epstein RM, Street RL Jr. The values and value of patient-centered care. Ann Family Med 2011;9:100-3.

9. Pelzang R. Time to learn: understanding patient-centered care. Br J Nurs 2010;19: 912-7.

10. Haywood C Jr, Williams-Reade J, Rushton $\mathrm{C}$, et al. Improving clinician attitudes of respect and trust for persons with sickle cell disease. Hosp Pediatr 2015;5:377-84.

11. Caocci G, Voso MT, Angelucci E, et al. Accuracy of physician assessment of treatment preferences and health status in elderly patients with higher-risk myelodysplastic syndromes. Leukemia Res 2015 [Epub ahead of print] pii: S01452126(15)00184-8. 